\title{
Emotional Temperament in Food-Related Metaphors: A Cross-Cultural Account of the Conceptualizations of SADNESS
}

\author{
Zahra Khajeh (Corresponding author) \\ School of Language Studies \& Linguistics, Universiti Kebangsaan Malaysia \\ 43600 Bangi, Selangor, Malaysia \\ Tel: 60-17-6124127 E-mail: khajehz7@gmail.com \\ Imran Ho-Abdullah \\ School of Language Studies \& Linguistics, Universiti Kebangsaan Malaysia \\ 43600 Bangi, Selangor, Malaysia \\ Tel: 60-3-8921-6481 E-mail: imranho@ukm.my \\ Tan Kim Hua \\ School of Language Studies \& Linguistics, Universiti Kebangsaan Malaysia \\ 43600 Bangi, Selangor, Malaysia \\ Tel: 60-3-8921-6568 E-mail: kimmy@ukm.my
}

Received: 05-07-2013

doi:10.7575/aiac.ijalel.v.2n.6p.54
Accepted: 07-08-2013

Published: 01-11-2013

URL: http://dx.doi.org/10.7575/aiac.ijalel.v.2n.6p.54

\begin{abstract}
What people in a society and culture eat or the way they consume their food may become a source domain for emotional temperament and therefore an implication for portrayal of their specific cultural models. Adopting the basic assumptions of the Lakoffian School on 'experiential realism' and 'universal embodiment' this study is an attempt to delve into the conceptual system of Persian in order to explore its specific socio-cultural motivations for the construction and semantic changes in the use of metaphorical concepts of SADNESS. The metaphorical uses of foodrelated concepts in Persian manifest that, in spite of some correspondences to those in English, SADNESS metaphorical concepts are distinctive in Persian. The conceptual metaphor variations reveal many vestiges of Hippocratic notions of humoral doctrine and Avicennian Traditional Medicine, suggesting that the cultural models of humoralism and dietetics have left their traces deeply in the Persians' belief systems. The effects, therefore, have been extended into Persian metaphoric language.
\end{abstract}

Keywords: conceptualization, embodiment, cognition, emotional temperament, sadness

\section{Introduction}

Human beings' dispositions, feelings, emotions, and attitude can be experienced in culinary concepts cross-culturally. That is due to the fact that humans' temperamental tendencies is not directly tangible and accessible to their comprehension, thus, it extensively needs to be experienced and conceptualized in terms of some other concrete, more familiar accessible concepts. In other words, through a discussion of dietetic concept of a certain culture, it will be possible to understand the manner the temperaments or emotional traits are manifested and highlighted with the semantic domain of food and eating. What people in a society and culture eat or like to eat, and whether they follow certain rules of dietetic may become an evaluation of their temperamental emotions and therefore an implication for portrayal of their specific cultural models.

According to Lakoffian researchers, an account of sharing experiences in all cultures by virtue of having the same type of physical bodies, the primary metaphors are universal. Calling into question the strong claims of 'embodiment' as an underlying motivation for emerging specific metaphorical concepts by Conceptual Metaphor Theory (CMT) (Lakoff \& Johnson, 1980, 1999), the close investigation of metaphorical uses of food-related concepts in Persian concerning basic temperamental emotion of SADNESS concepts will manifest that, in spite of some correspondences to those in English, such metaphorical concepts are distinctive. To show the distinction, it seems necessary to decompose the human emotion concepts into their constituent parts and to search for predominant aspects of individuals as temperaments, moods, and character traits. The present study, therefore, is an attempt to search for commonalities and disparities of food related metaphorical concepts with temperamental emotion of sadness in Persian comparing that with those of previously explicated by experiential thesis of embodiment in CMT.

To carry out a systematic analysis of SADNESS conceptual metaphors in present day Persian and English, thus, the researcher will begin with documented material, both printed and on-line databases of Persian food-related conventionalized metaphors from a variety of monolingual and bilingual dictionaries and some other lexicographical works such as dictionaries of idiomatic metaphorical expressions and thesauri, literary sources, and native speakers' 
intuition as corpus data. The analysis is mainly based on the author's intuition as a native speaker of Persian. It has been further crossed-checked informally by other natives of Persian.

The findings will then illuminate the cultural backgrounds of emotion terms in Persian leading us to portray the cultural motivations for their construction, or semantic changes. Since the general framework of this study is on the basis of the underlying assumptions made by CMT, it is expected that the findings of such a cognitive-semantic, cross-cultural study rectify this theory in general, and emotion conceptualizations in specific.

\section{Background of Study}

Sadness is generally characterized as an emotional reaction to loss of some sort. Lazarus (1991), for example, argues that sadness is a result of a loss, or a "failure of a central life value or role, or the loss of the positive regard of another" (p. 247). To make sense of this adaptive emotional temperament, English language portraits a high range of SADNESS metaphor conceptualizations. Within the framework of cognitive linguistics, Barcelona (1986) studied a significant number of sadness metaphors which have been modified by Kövecses (2000) as following:

Table 1. SADNESS metaphorical concepts and their corresponding linguistic manifestations (adopted from Lakoff, 1987; Kövecses, 2000)

\begin{tabular}{ll}
\hline SADNESS Conceptual Metaphor & Metaphorical Expression \\
\hline SADNESS IS DOWN & He brought me down with his remarks. \\
SADNESS IS DARK & He is in a dark mood. \\
SADNESS IS LACK OF HEAT & His remarks threw cold water on the party. \\
SADNESS IS LACK OF VITALITY & This was disheartening news. \\
SADNESS IS A FLUID IN A CONTAINER & I am filled with sorrow. \\
SADNESS IS VIOLENT PHYSICAL FORCE & That was a terrible blow. \\
SADNESS IS VIOLENT NATURAL FORCE & Waves of depression came over me. \\
SADNESS IS ILLNESS & Time heals all sorrows. \\
SADNESS IS INSANITY & He was insane with grief. \\
SADNESS IS BURDEN & He staggered under the pain. \\
SADNESS IS A LIVING ORGANISM & He drowned his sorrow back. \\
SADNESS IS CAPTIVE ANIMAL & His feelings of misery got out of hand. \\
SADNESS IS OPPONENT & He was seized by a fit of depression. \\
SADNESS IS SOCIAL SUPERIOR & She was ruled by sorrow. \\
\hline
\end{tabular}

As the above conceptualizations reveal, the source domains used to profile the SADNESS themes focus on the negative association of this emotional temperament. The concepts as LOWNESS, DARKNESS, LACK OF VITALITY, ILLNESS, and INSANITY are the cases that manifest the point. However as the discussion below shows, some important patterns and mappings of metaphor conceptualizations of SADNESS emotion have been left out of account in cognitive linguistic studies.

Lakoff's theory of conceptualization of emotions has triggered a wave of opposite reactions, criticizing CMT for its too much emphasis on the universality of human bodily experiences and embodiment as an underlying motivation for creating emotion metaphors and neglecting the systemic profound role of culture in human thought, reasoning, and understanding. For example, the direct connection between conceptualizing the emotional states and the physiological changes has been argued by Ungerer and Schmid (1996). They believe that most of physiological changes of anger can also be applied to a wide range of other different emotions. "ANGER, JOY and LOVE can cause an increase in body temperature (...); all three emotions may flush one's face. ANGER and JOY, but also SADNESS and FEAR can result in tears, an accelerated heartbeat and palpitations can be due to ANGER, FEAR, DISGUST and again LOVE, and general physical agitation seems to underly [sic] all the major emotions" (1996, Pp. 132-133). Deignan (2003), on the other hand, remarks that when conducting a purely synchronic study of languages, we should be aware of historical and cultural influences in the conceptualizations of the language. Not only the historical dimension of a language should be taken into account for non-transparent, opaque figurative expressions but " that many more transparent, metaphorical expressions are also historical in that they allude to knowledge that is still shared as part of our cultural repository, but no longer directly experienced" (Deignan, 2003, p. 270).

Geeraerts and Grondelaers (1995) challenge the purely synchronic research of CMT and argue that the conceptual metaphor of ANGER IS THE HEAT OF A FLUID IN A CONTAINER can well be traced back in the humoral theory while it has experienced reinterpretation:

Cultural models, i.e., the more or less coherent sets of concepts that cultures use to structure experience and make sense of the world are not reinvented afresh with every new period in the culture's development. Rather, it is by definition part of their cultural nature that they have a historical dimension. They can only fulfill their role of shaping a community's life if they have a historical permanence, that is, if they can be transmitted from generation to generation, assuring continuity over 
and above an individual's and an individual generation's activities (though not, to be sure, unaffected by them). If cognitive models are cultural models, they are also cultural institutions, and as such, they carry their history along with them: their institutional nature implies their historical continuity. It is only by investigating their historical origins and their gradual transformation that their contemporary form can be properly understood. (Geeraerts \& Grondelaers, 1995, Pp. 176-177).

They explicated their findings on the basis of a diachronic analysis of metaphorical expressions in Western conceptualizations of emotions, emphasizing the much more profound influence of medieval theories of four humors in emotion conceptions than the embodied accounts.

In his work Metaphor in Culture: Universality and Variation (2005), Kövecses demonstrates the absence of Conceptual Metaphor Theory in its cultural account and diachronic issues. He came to acknowledge that:

Obviously, then, the use of the humoral view as a form of cultural explanation extends far beyond anger and the emotions. In addition to being an account of emotional phenomena, it was an explanation of a variety of issues in physiology, psychology, and medicine. In other words, the humoral view was a key component of the classical-medieval cultural context and it exerted a major impact on the emergence of the European conception of anger as a fluid in a pressurized container. (Kövecses, 2005, p. 234).

The above mentioned works of linguists show that the study of metaphorical concepts is a matter of both diachronicity and synchronicity. In other words, for a full description of metaphorical meanings, the historical process applied to construct and develop polysemous aspects of terms as well as the semantic relations that link the words generic meanings to their metaphorical meanings should be taken into account. More importantly, on the other hand, metaphor studies whether diachronic or synchronic should go beyond the realm of pure linguistic perspectives, the underlying cultural experiences and traditions or as Shixiong Wu (2007, p. 20) suggests the 'em-minded cultural notions' that are "accumulated and deposited in a nation's worlds of knowledge, beliefs, habits, tradition, and even linguistic system" should be scrutinized as well. The cross-cultural integration made in this study, therefore, manifests why and how the embodied metaphor conceptualizations have been influenced by the cultural em-mindedness or cultural cognition, or as Maalej $(2004,2007)$ calls 'cultural embodiment of the mind'. The em-mindedness of cultural notions, as opposed to Lakoff and Johnson's embodiment, explicates the conventional beliefs which are rooted in a particular culture, its cultural inheritance, or notions unconsciously learnt in a non-embodied way.

This paper is, therefore, an attempt to narrow the existence gap in the experientialists' assumptions of conceptual metaphors. It suggests that the cultural model of humoralism and dietetics have mingled in Persians' life style as their effects have been extended into Persian metaphoric language, and cognitive conceptualizations. It means, in many ways, the food-related linguistic conventionalized usages of emotion concepts in Persian show many vestiges of Galenic Theory, and Iranian Traditional Medicine (ITM). Looking closely at the tradition of cultural concepts of dietetics and humoral doctrine reflected in metaphor conceptualizations in Persian, we will find new accesses to this language and its dominant em-minded cultural beliefs.

\section{The Four Humors and Their Corresponding Emotional Temperaments}

The idea of humoral theory is first codified by Sumerian and Egyptian philosophers and physicians. Hippocrates' (460370BC), a Greek physician, joined the human behavior to those of four humoral elements. The theory was later refined by the work of Galen (AD 131-200), a Roman scholar who developed the typology of temperaments from arkān 'elements' on the basis of Aristotle, Plato, and Empedocles. Arabs and Persian physicians further developed the humoral tradition into an ethno-medical system. Avicenna (Abu Ali Sina 980-1037), the $11^{\text {th }}$ century Iranian physician, influenced by traditional Greek and Islamic medicine and also Indian and Chinese healing teachings; in his book The Canon of Medicine (1029), fully explicated the theory of four humors, and the opposed qualities of garm 'hot' and sard 'cold', tar 'moist' and xošk 'dry' which are adopted from ITM. According to ITM, in the first stage of world beings' creation, elements of hot, cold, moist, and dry appeared, and in the next stage, they mixed together and arkān (original elements of human and non-human) as fire, air, water, and soil came into being. Plants, animals, and humans were then created respectively. Through the combination of these original simple bodies, the physical temperament or miza $\bar{j}$ is constituted. The four temperaments shaped in this way are 'hot and moist', 'hot and dry', 'cold and moist', and 'cold and dry'. Based on Iranian theory of humors, within the digestion process the foodstuffs are first transferred into particular constituents known as axlāt 'structural components'. Moreover, Avicenna emphasizes that the primary humors have their origins in food digestion. According to him, the humors function as nutrient substances utilized for body organs growth providing them with required energy. The four humors are categorized as dam 'blood', balqam 'phlegm', safrā 'yellow bile', and sodā 'black bile'.

According to ITM and based on four humors doctrine, people can be identified as having hot or cold nature with respect to their dominant body temperament essences. In other words, individuals' temperaments are categorized as sanguine, phlegmatic, choleric, and melancholic which are derived from their respective humoral constitutions as blood, phlegm, yellow bile, and black bile. Interestingly, the humors are attested to have their own temperaments as well. The blood is assigned to be hot and moist, phlegm humor cold and moist, yellow bile hot and dry, and black bile cold and dry temperaments. Accordingly, people with preponderance of hot humor depict the characteristic temperament of hot nature, and those with dominant cold humor features represent the cold nature people. The proper healthy diet and 
digestion maintains an optimum humoral balance. The following table summarizes the humoral theory and its characteristic sub categorization.

Table 2. Four humors and their correspondences in humoral doctrine

\begin{tabular}{lllll}
\hline Humor & Blood & Phlegm & black bile & yellow bile \\
\hline Qualities & hot and moist & cold ad moist & cold and dry & hot and dry \\
\hline Element & Air & Water & Earth & Fire \\
\hline Taste & Sweet & Salty & Sour & Bitter \\
\hline Color & Red & White & Black & yellow/red \\
\hline Origin & Heart & brain/ladder & Spleen & liver/stomach \\
\hline Temperament & Sanguine & Phlegmatic & Melancholic & Choleric \\
& 'hearthy', 'sensual' & 'sluggish', 'calm' & 'sad' & 'angry', \\
& & & & 'irascible' \\
\hline
\end{tabular}

As the table presents, the variant combinations of the humors in people manifests their dominant temperaments or complexions, as well as their physical and mental traits. An ideal individual, therefore, maintains a well-proportioned combination of four humors. The abundance of one of the body fluids or humors leads to a change in the people's mood and temperament. The excess of black bile with cold and dry characteristics, for example, results in a melancholic disposition.

On the other hand, dietetics as a key element for temperamental emotions in Persian is regarded as the doctrine of proper eating and drinking in order to be free from ailment. Avicenna views digestion process as poxt-e šodan 'heating' and 'cooking' the food by the body, i.e. while taking into the mouth, the food is transferred from its initial state, and is broken down into smaller nutrient particles. In this case, unconsciously, the digestive process is applied inside the body container and the food is absorbed and assimilated into blood streams and cells. It is to be noted that, the food selected for nutritive purposes should be in harmony with individual's temperament in order to produce balance in the body's humors activating the two of four humor properties as hot/cold and dry/moist in which the dominating humoral condition does not exist. A body with phlegmatic, for instance, is dominated by coldness and moisture and the pepper therefore is appropriate for the meal; however, a person with choleric suffers from heat and dryness and the consuming pepper reinforces the excess of humoral properties which already have dominated the body.

According to Geeraerts and Grondelaers (1995), the four humors doctrine "was not only the basis of pre-modern medical practice, it was integrated into a whole cosmology, with the establishment of correspondence between the humors and such diverse domains as the plant, and animal kingdoms, dietary practices, the seasons, and the planets" (Taylor, 1995: 13-14).

\section{Data Analysis and Discussion}

\subsection{FOOD Conceptual Metaphors and SADNESS Emotional States}

According to CMT, English language system conceptualizes sadness as fluid in a container which lacks 'heat' as in SADNESS IS FLUID IN A CONTAINER, and SADNESS LACKS HEAT (Kövecses 1998, 2000). Despite the widespread assumption that the source domain of HOT FLUID IN A CONTAINER is specific to ANGER emotion (Lakoff and Kovecses 1987), the Persian linguistic material of the current study reveals that HEAT conceptualization can also be applied to SADNESS metaphors as it has been scrutinized in detail in the discussion below.

\section{SADNESS IS A HOT SUBSTANCE IN A COTAINER}

There are several metaphorical expressions in Persian in which SADNESS, NERVOUSNESS and ANXIETY are associated with boiling substances in the body container giving rise to metaphor conceptualization SADNESS IS BOILING LIQUID. Consider the following expressions:

(1) delam juš mi-zane heart-POSS-1SG boil PROG-hit-3SG

My heart/stomach is boiling.

'I am sad/anxious/ worried.'

(2) as nārāhati-o negarāni del-am mesle sir-o serke mi-juše

from sadness and anxiousness heart-POSS-1SG like garlic and vinegar PROG-boil-3SG

My heart/stomach is boiling like garlic and vinegar

'I am highly sad/anxious/nervous.'

As the above examples show, the expressions contain the terms which are associated with boiling substances (liquid or solid) in the cooking frame. People's heart/stomach are regarded as a cooking pot with sadness, anxiety and nervousness emotions associated as ingredients (volatile substances) boiling over in this container. The metaphors suggest that the extreme intensity of SADNESS portrays boiling movements within a person (human body). While the heat is instantiated for sadness metaphors, the entailment projections are constructed between the boiling in the concrete source domain and the effects of sadness emotion on the person in the abstract target domain suggesting the general concept SADNESS IS A HOT FLUID IN A CONTAINER, and more specifically THE EFFECT OF SADNESS ON PERSON IS BOILING. 
The image schema of this cooking scenario instantiates the conceptual metaphor INTENSITY OF EMOTION IS DEGREE OF MOTION. This conceptualization accords with Grady's (1997) discussion on INTENSITY OF ACTIVITY IS HEAT, and INTENSITY OF EMOTION IS HEAT.

Interestingly, as (2) shows, the intensive boiling movement of the ingredients, garlic and vinegar, in a fermentation manner to produce pickle has been mapped onto the emotional state of anxiety, uneasiness, and agony. On the other hand, according to humoralism, the black bile (melancholic fluid) has the attributes of cold and dry, so the heat is expected to be absent while describing this emotional state. The heat, however, represents the feature INTENSITY as a key entailment in describing emotions, as in both sadness, and anger. It's to be noted that according to Traditional Medicine, the pickle is anxiety inducing food that weakens the magnesium level in the body which in turn increases the inner tension, and embarrassment. In addition, the humoral doctrine can also be interpreted in above expression where there is an implicit reference to the people's diet and their humoral balance and consequently their dominant emotional states. While melancholic people are thought to possess too much cold and dry humor, they are advised not to consume cold and dry foodstuffs (e.g. pickle). To restore humoral equilibrium, people need foodstuffs that are regarded to have counter effect properties (here hot and wet). Therefore, the mixture of garlic and vinegar will intensify the stress, anxiety, and uneasiness of those dominated by black bile.

\section{SADNESS IS COOKING FOOD}

In Persian, in addition to heated fluids concepts in a container, there are some other conventional metaphors representing certain emotional states through solid substances. They generally represent different cooking methods whether they use water (boiling), oil (frying), dry heat (baking/roasting), or over/under an open flame (grilling or broiling). Most of these cooking terms have metaphorical extensions in states of emotion in Persian as it is in English. In other words, the terms can be used in the semantic domain of cooking as well as anger, sadness, pain, anguish, and discomfort. The following expressions are the linguistic manifestations of the conceptual metaphorical theme SADNESS IS COOKING FOOD:

(3) del/jegar-am ro kabāb kard.

heart/liver-POSS-1SG ACC roast-PST-3SG

He roasted my heart/liver

'He made me extremely sad.'

(4) az bas azyat-am kard-e, mesle kabāb-e sar-e six šod-am

from amount bothering-OBJ.PRO-1SG do-PCTP-3SG, like kebab-GEN top-GEN spit become-1SG

He has bothered me so much that I look like grilled

'He has put me in much sadness/pain/agony.'

(5) dige tāqat na-dār-am, sorx-am kard-e.

more tolerance NEG-have-1SG, frying-OBJ.PRO-1SG do-PCTP-3SG

I cannot tolerate it anymore. He has fried me

'He has made me so much sad.'

In Persian, the expressions kabāb šodan 'being roasted', be six kešid-e šodan 'being grilled', and sorx šodan 'being fried'; metaphorically mean 'to feel extreme sadness, pain, and suffering'. The analogy between ' roasting, grilling, and frying the foods over fire and the extreme suffering a person experiences is based on the conceptual metaphor keys COOKING (ROASTING/GRILLING/FRYING) STANDS FOR EXTREME SADNESS, and SADNESS IS FIRE. Therefore, the above metaphors of various cooking methods map onto extreme suffering and the conceptual metaphor SADNESS IS ROASTING/GRILLING/FRYING allude to the intensity of sadness conceptualizing the mappings as EFFECT OF SADNESS ON PERSON IS BEING ROASTED/GRILLED/FRIED. In other words, the strong sadness is depicted in the image schema illustrated in different methods of cooking food by Persians representing INTENSITY OF EMOTION IS HEAT. Interestingly, in (3) based on the concept HEART/LIVER FOR THE PERSON, the metaphor profiles a cooking scenario image schema in which one's heart/liver undergoes extreme sorrow and pain, just as mutations happen to foodstuffs while they are cooking. The roasted, grilled, or fried heart/liver in Persian evokes the metaphor conceptualization of BEING SAD IS HAVING ONES HEART/LIVER COOKED (BROILED/FRIED/ROASTED). The melancholic state is very prone in building up tension and stress which are the consequences of impatience and irritability condition. It is interesting to know that the melancholic emotional state will be aggravated with foods which are heavily roasted or fried since it violates the balance of black bile. In other words, the aggravated black bile humor may be resulted from the way the foods are prepared and cooked. The foods are best if they are not fried, broiled, over dried, and indigestible since these different forms of cooking food cause rancidity and oxidation. It, in turn, intensifies the morbid state of black bile and leads melancholic people with delicate digestion to experience more tension and anguish as it is shown in (4) and (5) expressions.

\section{SADNESS IS BURNING FOOD}

The temperamental emotion of anger can also be possible in the case of melancholic state profiling the metaphor conceptualization of SADNESS IS BURNING. Consider the following examples in Persian:

(6) jegar/del-am ro suzund

liver/heart-POSS-1SG ACC burn-PST-3SG

He burnt my liver/heart.

'He made me so sad.' 
(7) del-am barā-š mi-suze

heart-POSS-1SG for-POSS-3SG PROG-burn-3SG

My heart is burning for him

'I feel so sorry/sad for him'.

(8) tā maqz-e ostoxān-am ro sozund

till marrow-GEN bone-POSS-1SG ACC burn-PST-3SG

He burnt me to my marrow of bone

'He made me extremely sad.'

\section{(9) mi-suz-am-o mi-sāz-am}

\section{PROG-burn-1SG and PROG-make-1SG}

I am burning, and adjusting myself with that

I feel so sad, but I do my best to tolerate that.

Samples (6) and (7) entail the burning of heart/liver in a COOKING frame to show the extreme degree of grief which conceptualizes the metaphor SADNESS IS BURNING in Persian. In fact, when making food, there may be a possibility that we fail, not using the right degree of heat leads the food to be raw, uncooked, or black burned. More precisely, the degree to which it occurs is on the basis of the cooking temperature, the time cooked, and the method we apply for cooking. The extreme fire/heat destroys the nutrients, and it may result in burning the food. The above expressions well evoke the conceptual metaphors EMOTION IS FIRE, and INTENSITY OF EMOTION IS HEAT in which sadness is conceptualized as an intense burning emotion that can consume people, mixing the physiological reactions with those of psychological ones. In other words, it seems there is something destructive with sadness and worry which is mapped into fire, with its negative potentiality of burning and consuming to the end (see also Yu, 2009, p. 250). Moreover, the burning scenario can also be used as the source of compassion in Persian as it can be interpreted from (7) as well. In addition to extreme sadness and worry, del suzāndan barāye kasi 'heart being burnt for someone' profiles the image schema of one's heart coming to feel kindness, mercy, or figuratively as being burnt. This conceptualization seems to reflect the Sufism beliefs about 'heart' characterizing del concept as the seat of spiritual love for God. In modern Persian, however, Sufism semantic coverage of love and affection has been broadened in scope and involves the emotional attachment and compassion to beloved and endeared ones (for an extended discussion of conceptualization of del 'heart-stomach' in Persian see Sharifian, 2008, Pp. 247-265). On the other hand, the SADNESS conceptualization can also be seen as hyperbole, exaggerating the sad condition through experiencing extensive heat in a destructive consuming manner as it is well demonstrated in (8), tā maqz-e ostoxān suxtan 'to be burned to the marrow of the bone/medulla'. By sadness, thus, one may feel consumed or destroyed since burning (putting on intensive fire) destroys things. Though the metaphors reflect the mapping of burning act to that of intensive grief emotion, it references a particular emotional condition called 'melancholic adust' or 'choleric melancholy' in Cannon of Medicine by Avecinna. Through this medical condition, the black bile (melancholy) is heated in the human body container (heart/liver) till it is burned, eventually resulting agitation, loss of control, and violence dominated by yellow bile of choleric temperament. In first place, the metaphor seems to profile the concept ANGER IS HEAT as underlined by Lakoff and Johnson (1980) and Lakoff and Kövecses (1987). The conceptual entailment of BURNING in a COOKING frame, however, much more accords with four-humor doctrine explicated in Iranian Traditional Medicine, emphasizing a close link between the cultural knowledge and practices with metaphorical expressions of SADNESS and ANGER in Persian. Moreover, the concepts of body heat, internal pressure, agitation, and body symptoms as face and neck redness are all attested in the four humor practices and subsequently in temperament descriptions. As the data for this study manifest, the Iranian Traditional Medicine is actively applied as self-treatment by lay medical practitioners. It seems that the effect of this lay practice has been extended beyond medical practices by experts and into metaphorical language and ultimately into cognitive conceptualization of Persians. It further denotes their particular cultural embodiment of temperamental emotions like ANGER and SADNESS suggesting that SADNESS IS HEAT is not embodied but em-minded.

\subsection{FOOD Conceptual Metaphors and SADNESS Emotional Qualities}

The food/eating domain can also attest the effect of a certain emotion on the body or temperament. Jackson (1986) found that the basic conceptual metaphors expressed by melancholic depressed sufferers are 'being in darkness', weighted down', and 'slowed down' which have their underlying source in Hippocratic notions of humoral doctrine. The melancholic feeling is deemed to be originated from an excess of black bile. In Iranian traditional medicine and in Persian language, the terms mālixuliā 'melancholia' and safrā-ye siyāh 'black bile' have been widely used and circulated by people in the ordinary conversations over centuries. Avicenna referred to melancholia as a "depressive type of mood disorder in which the person may become suspicious and develop certain type of phobias". The metaphorical theme of DARKNESS associated with sad depressive emotional valency shows a close correlation to the etymology of black bile and melancholia (melas 'black' and khole 'bile'). Moreover, the conceptual metaphors used to represent the effect of Persians' depressive feelings on their body and disposition seem to reveal a potential number of cultural models and values. Consider the following expressions in Persian:

(10) az qam-o nārāhati-ye zyād eštehā-m kur šod-e

from grief and sadness-GEN much appetite-POSS-1SG blind become-PCTP-3SG

Because of high degree of grief and sadness, my appetite was blind 'I feel extremely sad and anxious, and I have lost my appetite 
(11) az bas qose xord-am az eštehā oftād-am

from much grief eat-PST-1SG from appetite fall-PST-1SG

Because I grieved so much, I fell down from appetite.

'I was so sad that I lost my appetite.

(12) az in zendegi-ye la'nati oq-am mi-gire

from this life-GEN blasted nausea-SUB-PRO PROG-take-3SG

This blasted life makes me vomit

'I feel so much sad and worried.'

(13) engār tamāme qose-hā-ye ālam sar-e del-am mund-e/istād-e

as all grief-PL-GEN world top-GEN heart-POSS-1SG stay-PCTP-3SG

It seems all grieves of the world have stayed on the top of my heart/stomach

'I feel extremely sad/ I am extremely depressed.'

(14) tamām-e in saxti-hā-o moškelāt ru-ye del-am sangini mi-kone

all-GEN this hardship-PL and problems on-GEN heart-POSS-1SG heaviness

PROG-do-3SG

All these hardships and problems are heavy on my heart.

'I am highly depressed and sad.'

(15) del-am por az qam-o nārāhati-ye, mi-xā-m piš-e yeki xāli-š kon-am.

heart-POSS-1SG full from grief and sadness-is, PROG-want-1SG beside-GEN one empty-OBJ.PRO do-1SG

My heart is full of grief and sadness. I want to talk about it with someone to

make it empty

'I am extremely sad. I want to share my feeling with someone.'

(16) az esters-o negarāni tah-e del-am xāli šod-e

from stress and anxiousness bottom-GEN heart-POSS-1SG empty become-PCTP-3SG

From stress and anxiousness, the bottom of my heart has been empty

'I deeply feel sad and anxious.'

In (10), the expression kur šodan-e eštehā (literally as 'being blind in appetite') can be subsumed under the metaphor conceptualization of SADNESS IS DARKNESS. In this metaphor, the physical weakness and impaired sensory perception like 'blindness' connects the sad depressive feeling to that of 'darkness' pointing out the more specific conceptual metaphor SADNESS/DEPRESSION IS BLINDNESS. Expression (11), az eštehā oftādan (literally as 'falling down from appetite'), on the other hand, profiles the concept BEING DOWN that people usually use to describe their lowness of sprit while experiencing sadness and depression. According to humoral doctrine, the black bile which is originated from the element of earth, if excessive, causes the body to be weighted down and leads it to the melancholic emotion which accords with the previous Western studies metaphorizing SADNESS/DEPRESSION AS DOWN. Moreover, as the expression attests, the melancholic people show the signs of unwillingness to eat the food, or they complain their lack of appetite as the result of intensive distress and sorrow which gives rise to metaphorical concepts SADNESS IS UNWILLINGNESS TO EAT OR SADNESS IS LACK OF APPETITE.

According to traditional medicine, sadness is manifested not only with the effects of worry, stress, fear, and anxiety but also with the digestive disorders such as nausea and losing appetite. The mapping between the nausea and melancholic emotion is metaphorically conceptualized in (12) where ogh zadan 'throwing up the content of the stomach through the mouth' indicates that the people with melancholic temperament suffer from heavy load of sadness. In other words, they show potential tendency to vomit the excess of black bile (sadness, anguish, and distress) accumulated and sedimentated in their spleen profiling the metaphorical theme SADNESS IS ILLNESS OR SADNESS IS DISCOMFORT.

In example (13), the sense MOTIONLESS in the expression sar-e del mundan or sar-e del istädan 'being remained on the top of heart/stomach', and in (14) the concept HEAVINESS in sar-e del sangini kardan 'being heavy on the heart/stomach' are stemmed from the underlying physiological domain of difficulty in body movement due to overeating heavy food. The association is in a way that when a person is overeaten and faced the digestion disorders, the improper digestion leaves the food stagnated and forms damp and phlegm in the body which makes the body mobility difficult and slowed down suggesting the feeling of heaviness, sluggishness, and muzziness. This physiological event can be correspondent to highly sad, depressed people who experience the feeling of getting stuck and being unable to move due to heavy burden of their grieves and sorrows which connotes the conceptual metaphor SADNESS IS LACK OF MOVEMENT, and SADNESS IS HEAVY, or more specifically GRIEVES ARE IMPEDIMENTS TO MOTION. The concepts of BEING MOTIONLESS AND HEAVY suggested in melancholic-related metaphors seem to be highly manifested in the semantics of Persian term nāa-rāhati literally means 'inconvenience' and its symptoms and wide range of negative emotions including 'restlessness, depression, nervousness, persistent sadness and empty mood, fatigue and loss of interest in doing activities, feeling of being slow down, and hopelessness'. Interestingly, these ideas arise from the fact that too much amount of black bile in the body with cold, dry, and heavy qualities results in an exaggerated prominence of melancholic characteristics as in groundless anguish, distress, depression, and sluggishness. 
The metaphors (15) and (16) are also examples to account for how someone's emotional condition biases the resultant emotional reactions to a certain event. The feeling of fullness and emptiness is congruent with container image schema. The potentiality of a container suggests that it can be full or empty of its contents as it is presented with del 'heart/stomach' in Persian. The heart is treated as the locus of emotions, a container where a variety of emotions are located. The expression in (15) metaphorizes the difficult feeling of overeating or overfilling one's stomach as being overwhelmed with difficult emotions. In other words, the concept of fullness and emptiness illustrate the association between the concrete act of overeating food and an urge for emptying disturbing bowels with the uneasy feeling of being involved in intensive sorrow and distress, and the tendency to clarify the negative emotion. Experientially, with emotional distress we feel as if our heart is hollow or powerless, and with joy and happiness we feel as if our chest is full and swelled. The feeling of stress and anxiety, therefore, is conceptualized as empty hollow heart/stomach in (16); indicating an unexpected devastating which in turn profiles the feelings of powerlessness, weakness, and loss of support and hope.

As the above Persian expressions indicate, the conceptualizations of sadness and depression are associated with DARKNESS ( $k u r$ šodan-e eštehā), LOWNESS (az eštehā oftādan), MOTIONLESSNESS (sar-e del mundane), HEAVINESS (sar$e$ del sangini kardan), FULLNESS (por budan), and EMPTINESS/HOLLOWNESS (tah-e del xāli šodan). The metaphor conceptualizations of SADNESS IS DOWN, SADNESS IS DARK, SADNESS IS LACK OF VITALITY, and SADNESS IS FLUID IN A CONTAINER to a great extent show the consistency between Lakoffian assumptions of embodied physiological influence and the humoral doctrine. It corroborates the discussion by Geeraerts and Grondelaes (1995) that the present-day emotion conceptualizations are remnants of the four-humor trends suggesting that the emotions have driven their embodied manifestation from the humoralism.

\section{Concluding Remarks}

Due to its centrality to human life, food and eating practices are naturally rich with metaphorization. The food domain provides us with a strong visual image in different languages and cultures denoting various connotations and creating immediate links while referenced. Food-related metaphorical concepts use these associations through offering actual wordings which describe people's experiences, temperaments and emotions. Investigating what and how a nation eats, as well as the choice of their food ingredients, qualities, production, and the process of ingestion all can provide us with a valuable perspective into different aspects of their personal and cultural identities. As it is shown through the corpus data, SADNESS emotional temperament in Persian is conceptualized with much more complexity than the Lakoffian thesis of CMT assumptions. The study reveals that though our thinking is by part determined by embodied physiological factors and the metaphorical concepts that they give rise to, or vice versa, the em-minded cultural models are the prominent factors in constructing the cross-language, cross-conceptualization variations over the themes of emotional temperaments. The metaphors whether linguistically or conceptually, each in certain degrees, are the products of embodiment experiences, the em-minded cultural notions, and the interplay of both. In other words, while SADNESS IS A FLUID IN A CONTAINER is embodied, its manifestation as hot fluid in a container (heart-stomach) is an emminded cultural notion for Persians which is motivated and mediated by Iranian traditional worldviews.

Moreover, this study, to a great extent manifests an understanding of how del 'heart/stomach' body part has been an input for conceptualization of emotional temperaments of SADNESS in Persian. It is shown that most of the SADNESS conceptualizations include the image schemas that associate del 'heart/stomach' as the seat of melancholic emotional temperaments; a container that can be filled or emptied, with the 'sadness' as its ingredients that can be boiled, roasted, grilled, fried, and burned in this container, and it may affect the container to be heavy, hollow, dark, low, motionless, full, or empty. These conceptualizations of culinary themes, thus, provide the Persians with a basis for expressing a plethora of culturally-bound metaphorical expressions in which Persians' belly for most acts as s locus of melancholic emotional temperament or as Khajeh and Imran-Ho (2012, p. 84) assert as "the seat of negative emotions together with an abdomen centering conceptualization." Following the vestiges of humoral thesis and Iranian Traditional Medicine, it seems that the cultural models of ethno-medical tradition and Sufism have widely left their traces in the Persians' belief systems, the effects therefore, have been extended into Persian metaphoric language and cognitive conceptualizations.

\section{References}

Barcelona, A. (1986). On the Concept of Depression in American English:A Cognitive Aproach. Revista Canariade Estudios Ingleses, 12, 7-33.

Deignan, A. (2003). Metaphoric expressions and culture: An indirect link. Metaphor and Symbol 18, 255-271.

Geeraerts, D. \& Grondelaers, S. (1995). Looking back at anger: cultural traditions and metaphorical patterns. In J. Taylor and R. MacLaury (eds.) Language and the cognitive construal of the world. Berlin: Gruyter.

Grady, J. (1997). THEORIES ARE BUILDINGS Revisited. Cognitive Linguistics, 8(4), 267-290.

Jackson, M. (1986) Melancholia and depression: From Hippocratic time to modern times. New Haven, CT: Yale University Press.

Khajeh, Z.\& Imran-Ho, A. (2012). Persian culinary metaphors: a cross-cultural conceptualization. GEMA: Online Journal of Language Studies, 12 (1), 69-87. ISSN 1675-8021.

Kövecses, Z. (1998). Are There Any Emotion-Specific Metaphors? In Athanasiadou, A. and Tabakowska, E.(eds.). Speaking of Emotions: Conceptualization and Expression pp. 127-151. Berlin and New York: Mouton de Gruyter.

Kövecses, Z. (2000). Metaphor and emotion. New York/Cambridge: Cambridge University Press. 
Kövecses, Z. (2005). Metaphor in Culture: Universality and Variation. New York: Oxford University Press.

Lakoff, G. (1987). Women, Fire, and Dangerous Things: What Categories Reveal about the Mind. Chicago: University of Chicago Press.

Lakoff, G. \& Johnson, M. (1980). Metaphors We Live By. Chicago: The University of Chicago Press.

Lakoff, G. \& Johnson, M. (1999). Philosophy in the Flesh. New York: Basic Books.

Lakoff, G. \& Kövecses, Z. (1987). The cognitive model of anger inherent in American English. In Holland, D. \& Quinn, N. (eds.). Cultural models in language and thought pp. 195-221. Cambridge: Cambridge University Press.

Lazarus, R. S. (1991). Emotion and Adaptation. New York: Oxford University Press.

Maalej, Z. (2004). Figurative language in anger expressions in Tunisian Arabic: an extended view of embodiment. Metaphor and Symbol 19: 51-75.

Maalej, Z. (2007). The embodiment of fear expressions in Tunisian Arabic: Theoretical and practical implications. In Sharifian, F \& Palmer, G.B. (eds.). Applied Cultural Linguistics: Second Language Teaching/Learning and Intercultural Communication, pp. 87-104. Amsterdam/Philadelphia: John Benjamins.

Sharifian, F. (2008) Conceptualizations of del 'heart-stomach' in Persian. In F. Sharifian,Dirven, R., Yu, N., \& Niemeier, S. (eds.). Body, culture, and language: Conceptualisations of heart and other internal body organs across languages and cultures pp. 247-265. Berlin/New York: Mouton De Gruyter.

Shixiong WU. G (2007). A corpus-based synchronic comparison and diachronic interpretation of lexicalized emotion metaphors in English and Chinese. Ph.D. diss., Lingnan University.

Ungerer, F. \& Schmid, H. J. (1996). An Introduction to Cognitive Linguistics. London/New York: Longman.

Yu, N. (2009). The Chinese HEART in a Cognitive Perspective: Culture, Body, and Language. Berlin and New York: Mouton de Gruyter.

\section{Note}

Citations of Avicenna, together with Iranian Traditional Medicine, are from A Treatise on the Canon of Medicine of Avicenna, Incorporating a Translation of the First Book I.I.4, trans. O. Cameron Gruner (London: Luzac \& Co, 1930) 